\title{
Liver Apparent Diffusion Coefficient Changes during Telaprevir-Based Therapy for Chronic Hepatitis C
}

\author{
Nagihan İnan Gürcan ${ }^{1}$, Zakir Sakç11 ${ }^{1}$ Sıla Akhan², Elif Sargın Altunok², Aynur Aynığ ${ }^{2} u^{2}$, Yeşim Gürbüz , \\ Hasan Tahsin Sarisoy ${ }^{1}$, Gür Akansel ${ }^{1}$
}

\author{
${ }^{1}$ Department of Radiology, Kocaeli University School of Medicine, Kocaeli, Turkey \\ ${ }^{2}$ Department of Infectious Diseases and Clinical Microbiology, Kocaeli University School of Medicine, Kocaeli, Turkey \\ ${ }^{3}$ Department of Pathology, Kocaeli University School of Medicine, Kocaeli, Turkey
}

Background: Diffusion-weighted imaging (DWI) has become an established diagnostic modality for the evaluation of liver parenchymal changes in diseases such as diffuse liver fibrosis. Aims: To evaluate the parenchymal apparent diffusion coefficient value $(\mathrm{ADC})$ changes using diffusion-weighted imaging (DWI) during telaprevir-based triple therapy.

Study Design: Diagnostic accuracy study.

Methods: Seventeen patients with chronic hepatitis $\mathrm{C}$ virus (HCV) virus and twenty-five normal volunteers were included. All of the patients took 12-weeks of telaprevir-based triple therapy followed by 12-weeks of PEGylated interferon and ribavirin therapy. They were examined before treatment (BT), as well as 12-weeks (W12) and 24-weeks (W24) after treatment by 3 Tesla magnetic resonance imaging (MRI). DWI was obtained using a breath-hold single-shot echoplanar spin echo sequence. Histopathologically, liver fibrosis was classified in accordance with the modified Knodell score described by Ishak. Quantitatively, liver ADCs were compared between patients and normal volunteers to detect the contribution of DWI in the detection of fibrosis. In addition, liver ADCs were compared during the therapy to analyze the effect of antiviral medication on liver parenchyma.

Results: The liver ADC values of fibrotic liver parenchyma were significantly lower than those of the healthy liver parenchyma $(\mathrm{p}<0.001)$. However, we were not able to reach a sufficiently discriminative threshold value. The ADC values showed a declining trend with increasing fibrotic stage. No statistically significant correlation $(\mathrm{p}=0.204)$ was observed. Compared with those before treatment, the liver ADC values after telaprevir-based triple therapy were significantly decreased at W12. A significant increase in the liver ADC values was also observed after the cessation of telaprevir therapy at W24 with a return to initial values.

Conclusion: Liver ADC values appear to indicate the present but not the stage of liver fibrosis. DWI may be a helpful research tool for the assessment of antiviral drug effects.

Keywords: Liver, fibrosis, magnetic resonance imaging, diffusion-weighted magnetic resonance imaging, chronic hepatitis $\mathrm{C}$, telaprevir
Because hepatitis $\mathrm{C}$ virus (HCV) polymerase and protease are necessary for viral replication, they are targets for anti-HCV drugs. Several inhibitors of HCV protease such as telaprevir (Incivek, Vertex Pharmaceutical Inc.; MA, ABD), in combination with PEGylated alpha interferon (Pegintron; Schering, Berlin, Germany) and ribavirin (Ribasphere, DSM Pharmaceuticals; Warrendale, ABD) (PEG-IFN/RBV), have been ap- proved for the treatment of genotype 1 chronic $\operatorname{HCV}(1,2)$. The indication for treatment mainly depends on the presence of fibrosis, which motivates the need for biopsy. A non-invasive diagnostic approach is necessary to prevent the complications of biopsy (3).

Diffusion-weighted magnetic resonance imaging (DWI) has become an established diagnostic modality for the evaluation 
of liver parenchymal changes in diseases such as diffuse liver fibrosis. The diagnostic value of 1.5 Tesla (T) magnetic resonance imaging (MRI) for the detection of parenchymal fibrosis has been published in some reports (4-9). Only a few reports about the role of 3T MRI for determination of parenchymal fibrosis are present $(10,11)$. There is only one study in the Chinese literature about $\mathrm{ADC}$ value changes in liver during nucleoside analogue antiviral treatment in patients with active hepatitis $\mathrm{B}$ virus (HBV) (12). To our knowledge, the effect of telaprevirbased antiviral therapy for chronic HCV on liver apparent diffusion coefficient values (ADCs) has not been studied until now.

The present study has two aims. The first is to evaluate the relation between the ADC value and histopathologic stage of the liver fibrosis. The second is to study ADC changes due to telaprevir-based antiviral therapy.

\section{MATERIALS AND METHODS}

\section{Patients}

The study was approved by our institutional review board for human investigations, and informed consent was obtained from all patients. Nineteen HCV RNA positive patients (10 females and 9 males) were included in this retrospective study between May 2013 and May 2014. Two of them had to be excluded because of insufficient response to therapy (HCV RNA was positive during the therapy). Thus, $17 \mathrm{HCV}$ RNA positive patients ( 9 females and 8 males; mean age of $57.35 \pm 14.31$ years, range: 21-75 years) diagnosed with chronic HCV hepatitis and histopathologically proven liver fibrosis and 25 normal volunteers without liver disease (13 females and 12 males; mean age of $40.76 \pm 13.46$ years, range: $24-68$ years) were included in this study. All of them were treated for a total of 24-weeks: 12-weeks of telaprevir-based triple therapy; telaprevir combined with PEG-IFN/RBV followed by 12-weeks of PEG-IFN/RBV. All of them had negative HCV RNA at 12- and 24-weeks of therapy.

\section{Magnetic resonance imaging}

All of the patients were examined before treatment (BT), as well as 12-weeks (W12) and 24-weeks (W24) after the starting day of the therapy using a 3T MRI unit (Philips Achieva Intera; Eindhoven, The Netherlands) with a 16-channel sensitivity encoding (SENSE) body coil. Normal volunteers were studied only once. All of the patients initially underwent precontrast axial in-phase and out-of-phase T1-weighted (W) turbo field echo (TFE), axial and coronal T2-W single-shot turbo spin echo (SSh-TSE). Subsequently, axial SSh-SE echo-planar (EPI) DWI (TR:1930/TE:68/EPI factor:51) were obtained with b val- ues of 0 and $1000 \mathrm{~s} / \mathrm{mm}^{2}$. ADC maps were acquired from these images. Fat suppression was acquired with the SPAIR (spectral adiabatic inversion recovery) method. All images were obtained with parallel acquisition and a SENSE technique ( $R$ factor of 2). The acquisition was obtained in 15-20 minutes. All sequences consisted of multisection acquisitions (slice thickness/ intersection gap: $4 \mathrm{~mm} / 1 \mathrm{~mm}$ ) with imaging matrix of $112 \times 125$. The field of view (FOV) changes between 200 and $240 \mathrm{~mm}$.

\section{Histopathological assessment}

All patients underwent percutaneous liver biopsy within a mean delay of 3 days (range: 1-8 days) after MRI. A specialist liver pathologist (Y.G.) reviewed all the biopsy material and fibrosis of the parenchyma was categorized based on a 7-point scale in accordance with the modified Knodell score described by Knodell et al. (13). Fibrosis was staged on a 0-6 scale as follows: stage 0: no fibrosis; stage 1: fibrous expansion of some portal areas with or without fibrous septa; stage 2: fibrous expansion of most portal areas with or without fibrous septa; stage 3: fibrous expansion of most portal areas with occasional portal to portal bridging; stage 4: fibrous expansion of portal areas with marked portal to portal bridging; stage 5: marked bridging with occasional nodules; and stage 6: cirrhosis. Of the 17 patients, 3 had stage 1, 1 had stage 2, 4 had stage 3, 6 had stage 4 , and 3 had stage 5 fibrosis of the liver.

\section{Image analysis}

Quantitative analysis was performed in a work station with dedicated software (Philips MR workspace, Philips Medical System; Eindhoven, the Netherlands) by two radiologists (N.İ.H and Z.S) who were unaware of the biopsy results.

For quantitative evaluation of DWI, the ADC maps were obtained automatically from $b$ values of 0 and $1000 \mathrm{~s} / \mathrm{mm}^{2}$. The ADCs of the fibrotic (at BT, W12, and W24) and healthy liver were calculated. Three regions of interest (ROI) were placed over the right lobe with a mean size of $410 \mathrm{~mm}^{2}$ (range: 310 $480 \mathrm{~mm}^{2}$ ) to prevent interference from the adjacent abdominal wall or vascular and biliary structures. The average ADC was calculated from these three ADCs.

\section{Statistical evaluation}

Inter-observer agreement in the interpretation was evaluated using Kappa coefficient (K) statistic including 95\% confidence intervals (CI). The guidelines of Landis and Koch were followed for interpreting Kappa values: 0.00-0.20, slight agreement; 0.21-0.40, fair agreement; 0.41-0.60, moderate agreement; 0.61-0.80, substantial agreement; and 0.81-1.00, almost perfect agreement.

Histopathology was accepted as the gold standard for the statistical analysis. The ADCs of the fibrotic and healthy pa- 
renchyma were compared to assess the contribution of the $A D C$ values in the detection of the fibrosis. In addition, the liver ADCs at BT, W12, and W24 of the therapy were compared to determine how these parameters change during the antiviral therapy. The Kolmogorov-Smirnov test was used to evaluate if the data was normally distributed. The differences in the liver ADCs of the fibrotic and normal parenchyma and changes in the ADCs during the therapy were determined by Student's t-test. The differences in the mean ADCs among the fibrotic stages were analyzed by using one-way ANOVA. The relationship between the fibrotic stages and ADCs was studied using Kendall's tau- $b$ test. To determine the diagnostic value of ADCs for the detection of fibrosis and the sensitivity and specificity of the tests, receiver operating characteristic (ROC) analysis was performed. All statistical evaluations were performed using Statistical Package for Social Sciences version 18.0 (SPSS Inc.; Chicago, IL, USA) statistical software.

\section{RESULTS}

Results of the quantitative analysis of DWI are presented in Table 1. The inter-observer agreement for measurements of ADCs of the fibrotic (at BT, W12, and W24) and healthy liver were almost perfect $(\mathrm{K}=0.82, \mathrm{~K}=0.94, \mathrm{~K}=0.88, \mathrm{~K}=0.91)$ which indicates satisfactory reliability. The ADCs of the fibrotic parenchyma were significantly lower than those of the normal parenchyma $(p<0.001)$. The area under the ROC curve was $0.883 \pm 0.054$. However, we were not able to reach a sufficiently discriminative threshold value. There were no statistically significant differences in the $\mathrm{ADC}$ values among the fibrotic stages. The ADC values showed a trend to decline, with increasing fibrotic stage (Table 2). However, no statistically significant correlation $(\mathrm{p}=0.204)$ was observed.

Compared with the liver ADCs before treatment (Figure 1a), the liver ADCs after telaprevir-based triple therapy were significantly decreased at $\mathrm{W} 12(\mathrm{p}=0.045)$ (Figure $1 \mathrm{~b})$. Additionally, a significant increase in the liver ADCs was also observed after the cessation of telaprevir therapy at W24 (Figure 1c) with a return to initial values (significant difference between $\mathrm{W} 12$ and $\mathrm{W} 24$ at $\mathrm{p}=0.018$ and between BT and $\mathrm{W} 24$ at $\mathrm{p}=0.517$ ) (Figure 2).

\section{DISCUSSION}

The presence of liver fibrosis is a strict criterion to initiate antiviral treatment. A non-invasive diagnostic modality is necessary for this purpose to prevent the complications of biopsy
TABLE 1. Result of the quantitative analysis of the diffusion weighted imaging

\begin{tabular}{llcc}
\hline & & $\begin{array}{c}\text { Patients } \\
(\mathrm{n}=17)\end{array}$ & $\begin{array}{c}\text { Healthy volunteers } \\
(\mathrm{n}=25)\end{array}$ \\
\hline $\mathrm{ADC}$ & Before treatment & $0.74 \pm 0.23$ & $1.14 \pm 0.28$ \\
$\left(\mathrm{x} 10^{-3} \mathrm{~mm}^{2} / \mathrm{s}\right)$ & 12th week & $0.54 \pm 0.25$ & - \\
& 24th week & $0.68 \pm 0.24$ & - \\
\hline ADC: apparent diffusion coefficient. & &
\end{tabular}

TABLE 2. Result of the quantitative analysis of the diffusion weighted imaging in according to the fibrotic stage

\begin{tabular}{lcc}
\hline Stage & $\mathrm{n}$ & $\begin{array}{c}\mathrm{ADC} \\
\left(\mathrm{x} 10^{-3} \mathrm{~mm}^{2} / \mathrm{s}\right)\end{array}$ \\
\hline 1 & 3 & $0.84 \pm 0.25$ \\
2 & 1 & 1.02 \\
3 & 4 & $0.88 \pm 0.15$ \\
4 & 6 & $0.56 \pm 0.15$ \\
5 & 3 & $0.48 \pm 0.12$ \\
\hline ADC: apparent diffusion coefficient. & &
\end{tabular}
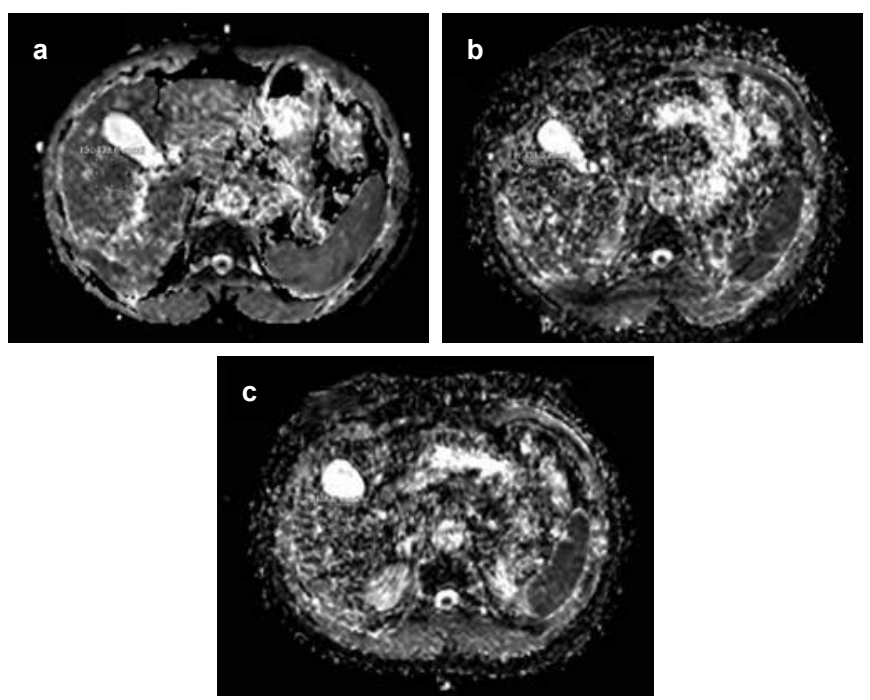

FIG. 1. a-c. Liver $A D C$ (apparent diffusion coefficient) changes in a 66 -year-old woman with stage 4 chronic viral hepatitis C. Liver ADC values before therapy were calculated as $0.92 \times 10-3 \mathrm{~mm}^{2} / \mathrm{s}(\mathrm{a})$; liver $A D C$ values 12 weeks after therapy were calculated as $0.69 \times 10-3$ $\mathrm{mm}^{2} / \mathrm{s}$; (b); liver ADC values 24 weeks after therapy were calculated as $1.10 \times 10^{-3} \mathrm{~mm}^{2} / \mathrm{s}$ (c).

in patients with chronic HCV (3). MRI could be a non-invasive method for this purpose because it provides a very good evaluation of the liver morphological alteration. In the literature, parenchymal signal and contrast enhancement changes of the liver parenchyma have been analyzed for this purpose. The diagnostic accuracy have been reported to vary between $68 \%$ and $91 \%$ (14). Recently, MRI perfusion (15) and elastography (16) techniques have also been conducted. DWI has 


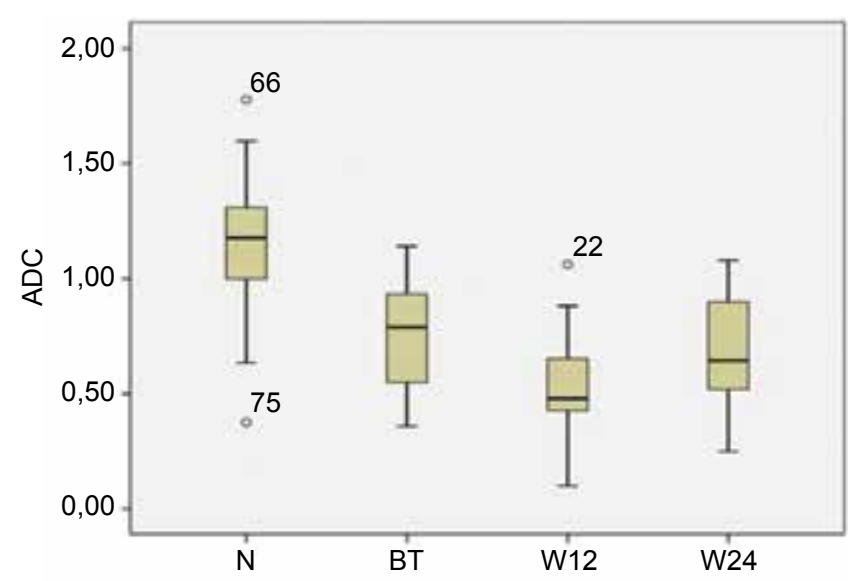

FIG. 2. Variations in the liver ADC (apparent diffusion coefficient) values during triple therapy.

been increasingly utilized to evaluate diffuse liver pathologies (4-11) and could provide additional information in tissue characterization. The diagnostic value of this technique on $1.5 \mathrm{~T}$ MRI systems has been reported (4-9). Data on the use of 3T systems in the evaluation of liver fibrosis are scarce $(10,11)$. A higher magnetic field results in a higher signal, permitting higher resolution. However, available results are suggesting that $\mathrm{ADC}$ quantification is equivalent compared to $1.5 \mathrm{~T}$. One limitation of $3 \mathrm{~T}$ is the increased susceptibility resulting in image distortion. This technique is still requires further optimization (17).

Diffusion may be interpreted quantitatively using the ADC maps without T2 effect. Ichikawa et al. (18) reported that the ADC should be measured from the right lobe on high-b-value DWI to avoid the perfusion effect. This is why the ADCs were obtained from the right lobe with a high $\mathrm{b}$ value in our study. In previous manuscripts, the mean ADCs of fibrotic parenchyma were lower than those of healthy parenchyma (4-11). Koinuma et al. (5) demonstrated a significant negative correlation between hepatic ADC and fibrosis score. Girometti et al. (11) also reported lower ADC in cirrhotic livers compared to normal controls, and showed an area under the curve (AUC) of 0.93 , with sensitivity of $89.7 \%$ and specificity of $100 \%$ for diagnosing cirrhosis. Similar to previous reports, the mean ADC values were significantly lower than those of normal parenchyma in our study. This is most likely due to reduced diffusion. Chronic HCV infection leads to an increase in the extracellular matrix, particularly collagen fibers. Diffusion may be restricted by the presence of excess collagen, consequently decreasing the ADCs in fibrotic parenchyma (19).

After the initial infection with $\mathrm{HCV}$, chronic hepatitis $\mathrm{C}$ develops in most people, while cirrhosis and hepatocellular carcinoma (HCC) develop in later years in a subgroup. The current standard of therapy for these patients is PEG-IFN/ RBV for 48 -weeks. Unfortunately, less than $50 \%$ of patients respond to this therapy (20). The sustained virologic response (SVR) with telaprevir was reportedly approximately $70 \%-80 \%$ in previous reports (1). This treatment has the potential to decrease the risk of cirrhosis, complications of liver disease, future HCC, and mortality. Telaprevir must be used combined with PEG-IFN/RBV for chronic HCV therapy. This combination may cause some side effects, including itching, rash, anemia, nausea, fatigue, diarrhea, vomiting, anal or rectal problems, taste changes, and signs or symptoms of dehydration (2). More recently, renal impairment has been reported with telaprevir (20). In that report, the model for end-stage liver disease (MELD) score was also used to evaluate specific effects of treatment on liver health. An increase in the MELD score was reported in the conclusion. However, the MELD score is calculated using serum bilirubin and creatinine levels and may not be reliable to evaluate liver health due to variations in creatinine levels during triple therapy. In our study, the liver ADCs after telaprevir-based triple therapy were significantly decreased at W12, and a significant increase in liver ADCs was observed after cessation of telaprevir therapy at W24 with a return to initial values. It appears that telaprevir treatment leads to restricted diffusion. This restriction seems reversible with a return to initial liver ADCs after Telaprevir withdrawal. A decrease in liver ADCs could be associated with various ultrastructural changes such as cell necrosis/apoptosis and inflammatory cell infiltration. Further electron microscopic studies are needed to decipher the effect of telaprevir on hepatocytes, or the space of Disse.

The main limitation encountered in this study was the absence of histopathologic correlation during and after therapy to assess the parenchymal changes in the liver. Another important limitation was that only the responders have been included in this study, due to the fact that in case of insufficient response, therapy needed to be ceased. Certain inherent imperfections of DWI resulted in several limitations in our study. The EPI sequence has a relatively low signal-to-noise ratio (SNR), which results in significant image distortion. Furthermore, EPI has additional anatomic distortion because of susceptibility effects.

In conclusion, liver ADC values appear to indicate the present but not the stage of liver fibrosis. DWI could be incorporated into routine MRI protocols to evaluate parenchymal fibrosis. It may be a helpful research tool for the assessment of antiviral drug effects. It appears that Telaprevir-based triple therapy decreases liver ADCs. Cautious clinical monitoring should focus not only on frequent side effects but also on liver function. 
Ethics Committee Approval: Ethics committee approval was received for this study from the ethics committee of Kocaeli University School of Medicine (Date of approval:09 April 2013; number: 2013/109).

Informed Consent: Written informed consent was obtained from participants who participated in this study.

Peer-review: Externally peer-reviewed.

Author contributions: Concept - N.İ.G.; Design - N.İ.G., S.A.; Supervision - N.İ.G., S.A.; Resource - N.İ.G., S.A., G.A.; Materials N.İ.G., S.A.; Data Collection and/or Processing - Z.S., E.S.A., A.A., Y.G.; Analysis and/or Interpretation - N.İ.G., H.T.S., Y.G. ; Literature Search - N.İ.G., G.A.; Writing - N.İ.G., G.A.; Critical Reviews - S.A., E.S.A., A.A.

Conflict of Interest: No conflict of interest was declared by the authors.

Financial Disclosure: The authors declared that this study has received no financial support.

\section{REFERENCES}

1. Shiffman ML, Esteban R. Triple therapy for HCV genotype 1 infection: telaprevir or boceprevir? Liver Int 2012;32(Suppl 1): 54-60. [CrossRef]

2. Forestier N, Zeuzem S. Triple therapy with telaprevir: results in hepatitis $\mathrm{C}$ virus-genotype 1 infected relapsers and non-responders. Liver Int 2012;32(Suppl 1):44-50. [CrossRef]

3. Tsochatzis EA, Crossan C, Longworth L, Gurusamy K, Rodriguez-Peralvarez M, Mantzoukis $\mathrm{K}$, et al. Cost-effectiveness of noninvasive liver fibrosis tests for treatment decisions in patients with chronic hepatitis C. Hepatology 2014;60:832-43. [CrossRef]

4. Aubé C, Racineux PX, Lebigot J, Oberti F, Croquet V, Argaud $\mathrm{C}$, et al. [Diagnosis and quantification of hepatic fibrosis with diffusion weighted MR imaging: preliminary results]. $J$ Radiol 2004;85:301-6. [CrossRef]

5. Koinuma M, Ohashi I, Hanafusa K, Shibuya H. Apparent diffusion coefficient measurements with diffusion-weighted magnetic resonance imaging for evaluation of hepatic fibrosis. J Magn Reson Imaging 2005;22:80-5. [CrossRef]

6. Taouli B, Tolia AJ, Losada M, Babb JS, Chan ES, Bannan MA, et al. Diffusion-weighted MRI for quantification of liver fibrosis: preliminary experience. AJR Am J Roentgenol 2007;189:799806. [CrossRef]

7. Luciani A, Vignaud A, Cavet M, Nhieu JT, Mallat A, Ruel L, et al. Liver cirrhosis: intravoxel incoherent motion MR imaging-pilot study. Radiology 2008;249:891-9. [CrossRef]

8. Lewin M, Poujol-Robert A, Boëlle PY, Wendum D, Lasnier E, Viallon $\mathrm{M}$, et al. Diffusion-weighted magnetic resonance imag- ing for the assessment of fibrosis in chronic hepatitis C. Hepatology 2007;46:658-65. [CrossRef]

9. Wang Y, Ganger DR, Levitsky J, Sternick LA, McCarthy RJ, Chen ZE, et al. Assessment of chronic hepatitis and fibrosis: comparison of MR elastography and diffusion-weighted imaging. AJR Am J Roentgenol 2011;196:553-61. [CrossRef]

10. Watanabe H, Kanematsu M, Goshima S, Kondo H, Onozuka M, Moriyama N, et al. Staging hepatic fibrosis: comparison of gadoxetate disodium-enhanced and diffusion-weighted MR imaging--preliminary observations. Radiology 2011;259:142-50. [CrossRef]

11. Girometti R, Esposito G, Bagatto D, Avellini C, Bazzocchi M, Zuiani C. Is water diffusion isotropic in the cirrhotic liver? a study with diffusion-weighted imaging at 3.0 Tesla. Acad Radiol 2012;19:55-61. [CrossRef]

12. Sun L, Xia Z, Gong J, Ma J, Huang G, Zang D, et al. Monitor $\mathrm{ADC}$ value changes in liver before and after receiving nucleoside analogue antiviral treatment in patients with active hepatitis $\mathrm{B}$ virus using diffusion-weighted magnetic resonance imaging value of apparent diffusion coefficient in liver cirrhosis. Journal of Medical Imaging 2013;6:200903027.

13. Knodell RG, Ishak KG, Black WC, Chen TS, Craig R, Kaplowitz $\mathrm{N}$, et al. Formulation and application of a numerical scoring system for assessing histological activity in asymptomatic chronic active hepatitis. Hepatology 1981;1:431. [CrossRef]

14. Aguirre DA, Behling CA, Alpert E, Hassanein TI, Sirlin CB. Liver fibrosis: noninvasive diagnosis with double contrast material-enhanced MR imaging. Radiology 2006;239:425-37. [CrossRef]

15. Hagiwara M, Rusinek H, Lee VS, Losada M, Bannan MA, Krinsky GA, et al. Advanced liver fibrosis: diagnosis with 3D whole-liver perfusion MR imaging--initial experience. Radiology 2008;246:926-34. [CrossRef]

16. Rouvière $\mathrm{O}$, Yin $\mathrm{M}$, Dresner MA, Rossman PJ, Burgart LJ, Fidler JL, et al. MR elastography of the liver: preliminary results. Radiology 2006;240:440-8. [CrossRef]

17. Rosenkrantz AB, Oei M, Babb JS, Niver BE, Taouli B. Diffusion-weighted imaging of the abdomen at 3.0 Tesla: image quality and apparent diffusion coefficient reproducibility compared with 1.5 Tesla. J Magn Reson Imaging 2011;33:128-35. [CrossRef]

18. Ichikawa T, Haradome H, Hachiya J, Nitatori T, Araki T. Characterization of hepatic lesions by perfusion-weighted MR imaging with an echoplanar sequence. AJR Am J Roentgenol 1998;170:1029-34. [CrossRef]

19. Tosun M, Inan N, Sarisoy HT, Akansel G, Gumustas S, Gürbüz Y, et al. Diagnostic performance of conventional diffusion weighted imaging and diffusion tensor imaging for the liver fibrosis and inflammation. Eur J Radiol 2013;82:203-7. [CrossRef]

20. Virlogeux V, Pradat P, Bailly F, Funingana G, Gonçalves F, Maynard M, et al. Boceprevir and telaprevir-based triple therapy for chronic hepatitis $\mathrm{C}$ : virological efficacy and impact on kidney function and model for end-stage liver disease score. $J$ Viral Hepat 2014;21: e98-107. [CrossRef] 